\title{
Soil Water and Salt Transport and its Influence on Groundwater Quality: A Case Study in the Kongque River Region of China
}

\author{
Weihong Dong ${ }^{1,3}$, Chuanlei Wen ${ }^{1-4}$, Pan Zhang ${ }^{5}$, Xiaosi Su ${ }^{1,3 *}$, \\ Fengtian Yang ${ }^{1,3}$
}

${ }^{1}$ Key Laboratory of Groundwater Resources and Environment (Jilin University), Ministry of Education, Changchun, China

${ }^{2}$ Jilin Provincial Key Laboratory of Water Resources and Environment, Jilin University, Changchun, China ${ }^{3}$ Institute of Water Resources and Environment, Jilin University, Changchun, China ${ }^{4}$ College of New Energy and Environment, Jilin University, Changchun, China

${ }^{5}$ Jilin Geophysical Prospecting and Surveying Company, Changchun, China

Received: 6 February 2018

Accepted: 28 March 2018

\begin{abstract}
Unreasonable exploitation of groundwater resources in the Kongque River region has led to a decline in the groundwater table, groundwater salinization, and other geo-environmental problems. Therefore, this study supplements the studies on soil water and salt transport in the Kongque River region, and provides a new method for the prevention of groundwater salinization in arid and semiarid regions. In this study, soil column experiments were carried out to investigate the influence of lithological structures of the unsaturated zone, water quality, and methods of irrigation on soil water and salt transport. Based on the data from the experiment, a one-dimensional model of soil water and salt transport was built to predict the impact of long-term irrigation on groundwater quality using Hydrus1D. The results showed that groundwater TDS increased in the predicted scenarios and that groundwater quality was greatly influenced by irrigation water with high TDS values. The influence of long-term irrigation on groundwater quality was smallest for drip irrigation, which can save water and should be promoted. The influence of irrigation on groundwater quality was largest for flood irrigation. If flood irrigation cannot be avoided, then it is recommended that water with a TDS below $2 \mathrm{~g} / \mathrm{L}$ should be used.
\end{abstract}

Keywords: Kongque River region, irrigation, unsaturated zone, soil water and salt transport, groundwater

*e-mail: suxiaosi@jlu.edu.cn 


\section{Introduction}

In arid and semi-arid regions, soil salinization and water shortages have become a serious threat to food safety from cultivated land because of scarce rainfall, strong evaporation, unreasonable use of water resources, and unfavorable drainage conditions [14]. In the short term, the use of irrigation water with high TDS concentration in these areas can: 1) cause soil salinization and soil pore clogging [5], 2) reduce soil permeability [6], and 3) affect the stability of soil structure and change the physical and chemical properties of soil [7]. In the long term, salt transport in the unsaturated zone can cause aquifer salinization [8]. Although significant progress has been made in the control of soil salinization, these problems have not been eliminated. In China, India, the United States, Tunisia, and South Africa, 9-25\% of the irrigated area suffers from soil salinization. In Pakistan, the estimated proportion is even higher at more than $25 \%$ [9]. Every year, $2 \times 10^{5} \mathrm{~km}^{2}$ to $3 \times 10^{5} \mathrm{~km}^{2}$ of irrigated land is degraded and/or destroyed, globally, by the effects of soil salinization, and about $1.5 \%$ of irrigated areas are, as a consequence, no longer suitable for agricultural cultivation [10]. Therefore, the study of soil water and salt transport is of great significance for the reasonable utilization of water resources, the control of soil salinization, and the prevention of groundwater salinization.

Over the past two decades, scientists have invested considerable research effort in predicting the shortterm and long-term effects of irrigation with different water quality on the unsaturated zone, grain production, and groundwater using numerical models [11-12]. The Hydrus-1D model, which describes one-dimensional water movement and solute transport in the unsaturated zone, is a very important tool for analyzing the effects of irrigation water on groundwater, and for predicting the effects of irrigation water on soil water and salt transport [13]. The Hydrus-1D model is a computer model based primarily on the Richards equation and the convective dispersion equation [14]. Using the Hydrus1D model is less expensive than using site tests, reduces the interference of site factors, and also allows for the prediction of minor changes in groundwater quality caused by long-term irrigation [15-18]. The Hydrus-1D model has been successfully applied in many studies on soil salinization, groundwater salinization, and plant

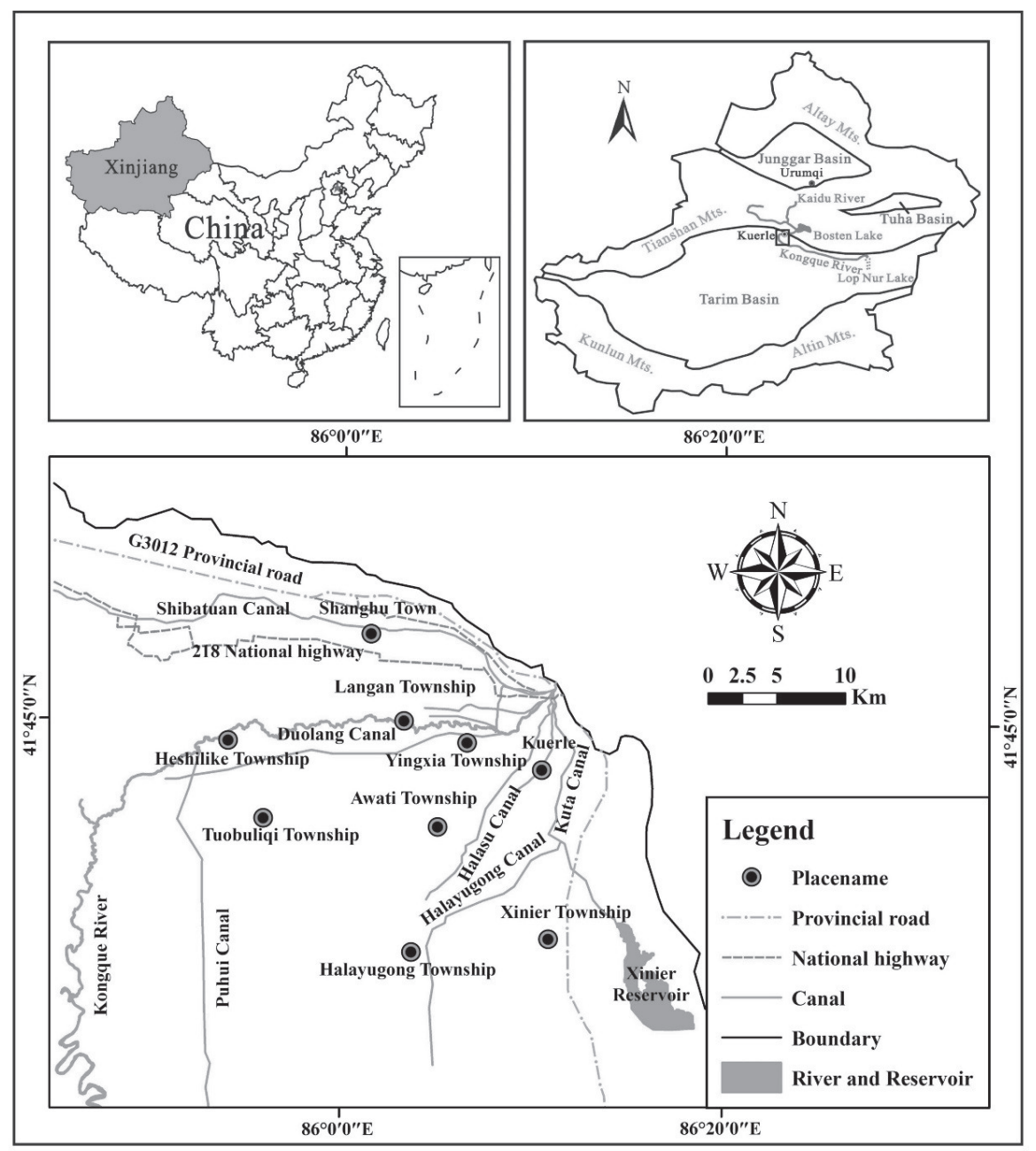

Fig. 1. Location of the study area. 
growth [19-21]. Therefore, in this study the Hydrus-1D model was used to simulate the soil column experiment and predict the effect of long-term irrigation on groundwater quality in different scenarios.

Kuerle is the source of the Western-Region Cultures. It is also an important transportation hub and material distributing center in Xinjiang, China. In recent years, the unreasonable exploitation of groundwater resources in the Kongque River region has led to a decline in the groundwater table, groundwater salinization, and other geo-environmental problems [22]. In the study area, confined water (TDS values between about 0.6-5.2 g/L) is usually used for irrigating cotton. For cations, $\mathrm{Na}^{+}$ was the dominant cation with an average concentration of $588.97 \mathrm{mg} / \mathrm{L}$. For anions, $\mathrm{Cl}^{-}$was the dominant anion with an average concentration of $943.34 \mathrm{mg} / \mathrm{L}$. Longterm irrigation has caused a large amount of salt from the unsaturated zone to be transported to the aquifer, and this has increased the TDS of the phreatic water. Over the past few decades, many scholars have studied soil water and salt transport in this region. Wang (2014) reported that mulched drip irrigation during the growing season caused an increase in salinity in the root zone of cotton [23]. Zhang (2015) presented a new numerical simulation method (a finite analytic method) for solving the unsaturated flow equation and concluded that the finite analytic method had some advantages at simulating the water movement of the unsaturated zone [24]. Li (2016) advocated that the accumulated salt could be effectively leached out of soil profile under a large amount of irrigation with brackish water of $90.6 \mathrm{~mm}$ [25]. Zhang (2016) developed a finite analytic method based on the mixed-form Richards' equation. It was shown that this new approach minimized mass balance errors and truncation errors associated with most numerical approaches [26]. Wang (2017) investigated flow dynamics in a thick unsaturated zone using a field experiment. It was concluded that flow dynamics in the unsaturated zone was mainly driven by gravity but modified by temperature, rainfall, plants, and groundwater variations [27]. Chen (2018) conducted two-year field experiments in a cotton field. They found that the average soil moisture content and soil salinity in the root zone were higher for brackish water irrigation treatment than for freshwater irrigation treatment [28]. However, previous studies on soil water and salt transport in the Kongque River region focused on the factors influencing salt accumulation and the control of salinization. Little research has been conducted on the effect of long-term irrigation on groundwater quality. Therefore, this study supplements the studies on soil water and salt transport in the Kongque River region, and provides a new method for the prevention of groundwater salinization.

The objectives of this study are: 1) to analyze the variation trends in water content and TDS concentration in unsaturated zone during irrigation with time and depth, and to study the processes controlling groundwater hydrochemistry using a laboratory soil column experiment; 2) to establish a one-dimensional model of soil water and salt transport based on the laboratory experiment data using the Hydrus-1D model; and 3) to predict the influence of long-term irrigation on groundwater quality for different lithological structures and irrigation water quality.

\section{Study Area}

The study area is located in southwestern Kuerle city at the southern foot of the Tianshan Mountains in the Xinjiang Uygur Autonomous Region, and covers an area of about $1547 \mathrm{~km}^{2}$ (Fig. 1). The overall terrain is high in the northeast and low in the southwest, with an elevation of 890-960 m. Agricultural planting occupies most of the area. The main crop grown is cotton.

The study area is located in the hinterland of Eurasia, away from the sea, with a typical continental arid climate in a warm temperate zone. Summers are hot while winters are cold. The temperature difference between day and night is large $\left(10-15^{\circ} \mathrm{C}\right)$. Precipitation is low, with an average of $58.6 \mathrm{~mm} / \mathrm{a}$, while the evaporation is intense, averaging $2788.2 \mathrm{~mm} / \mathrm{a}$ (Fig. 2). The prevailing northeast wind blows throughout the year.

The lithological structures in the unsaturated zone can be divided into two categories: 1) the shallow groundwater area, where from top to bottom the lithology is sub-clay, silty sand, medium-fine sand with gravel, medium-coarse sand, and silty sand, while the average thickness is $3.0 \mathrm{~m}$; and 2) the deep groundwater area, where from top to bottom the lithology is sub-clay and silty sand, while the average thickness is $13.5 \mathrm{~m}$. The main type of groundwater in the study area is quaternary pore water. In the agricultural irrigation area, groundwater is mainly recharged by infiltration of irrigation water. Groundwater discharge occurs mainly as a result of artificial mining [29], evaporation, transpiration, and runoff.

The water sources for agricultural irrigation in the study area were from surface water and groundwater. And the water consumption of the two kinds of water were $2.73 \times 10^{8} \mathrm{~m}^{3} / \mathrm{a}$ and $6.21 \times 10^{8} \mathrm{~m}^{3} / \mathrm{a}$, respectively,

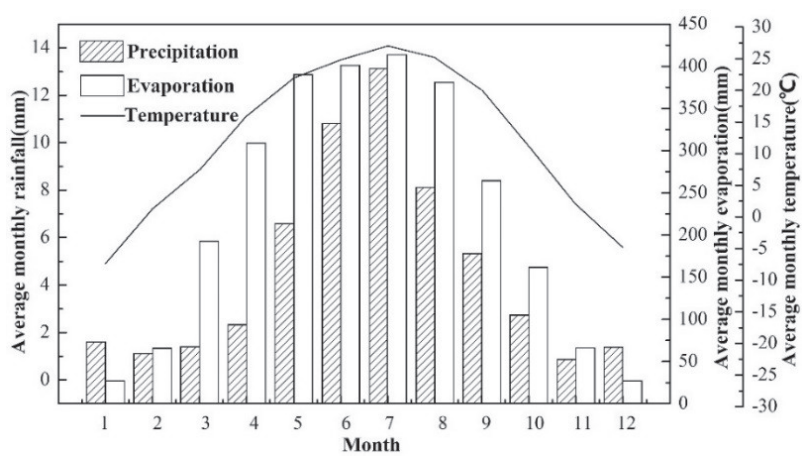

Fig. 2. Meteorological map of the study area. 
Table 1. Physical properties of soil samples.

\begin{tabular}{|c|c|c|c|c|}
\hline Lithology & Sub-clay & Medium-fine sand with gravel & Medium-coarse sand & Silty sand \\
\hline Dry density $\left(\mathrm{g} / \mathrm{cm}^{3}\right)$ & 1.35 & 1.66 & 1.55 & 1.50 \\
\hline$<0.075 \mathrm{~mm}(\%)$ & 100 & 0 & 5 & 10 \\
\hline $0.075-0.25 \mathrm{~mm}(\%)$ & 0 & 10 & 45 & 50 \\
\hline $0.25-0.5 \mathrm{~mm}(\%)$ & 0 & 26 & 35 & 30 \\
\hline $0.5-2 \mathrm{~mm}(\%)$ & 0 & 60 & 0 & 10 \\
\hline$>2 \mathrm{~mm}(\%)$ & 0 & 4 & & 0 \\
\hline
\end{tabular}

in 2013. Surface water is the main water source of irrigation in the surrounding areas of the Kongque River and Xinier Reservoir. In recent years, the annual runoff of the Kongque is decreasing, surface water is used for irrigation in the spring irrigation period, while groundwater is used for irrigation in the crop growth period. In most areas of the study area, confined water is the only water source for irrigation. Excessive exploitation of groundwater in the dry season has led to a decline in the groundwater table. In addition, the salt content of the unsaturated zone in the cultivated area is relatively high (The average value is $2.08 \mathrm{~g} / \mathrm{kg}$ ). A large amount of salt in the unsaturated zone was brought into the groundwater during the irrigation process, which led to groundwater salinization. According to the groundwater chemistry data of the study area in September 2014, the TDS content of groundwater is generally high: the average TDS content in the phreatic water is $4.1 \mathrm{~g} / \mathrm{L}$, while it is $3.0 \mathrm{~g} / \mathrm{L}$ in the confined water.

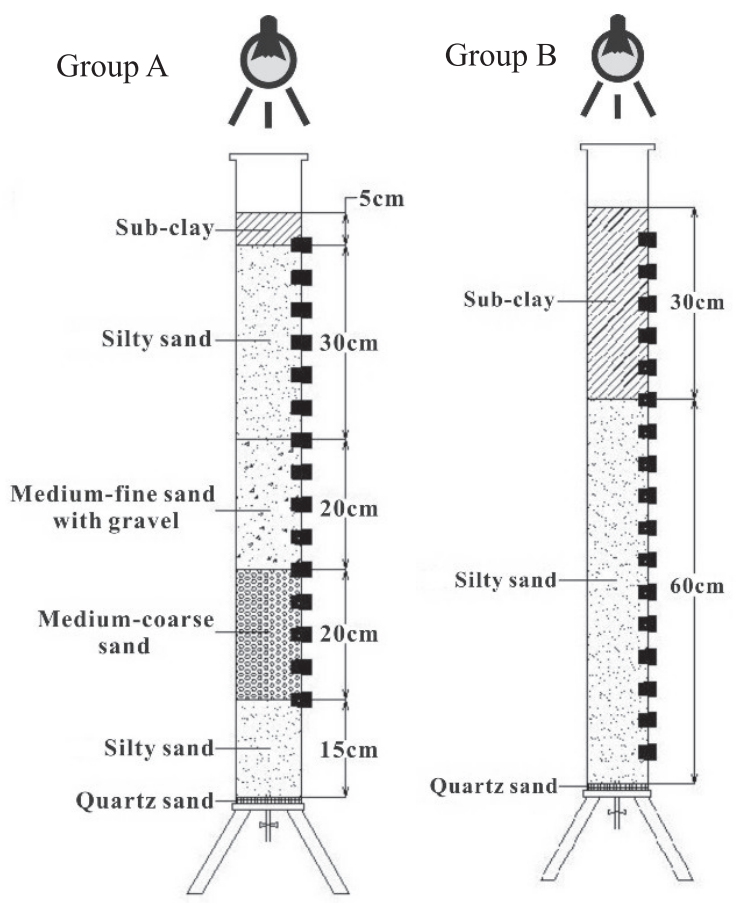

Fig. 3. Device diagram of soil column experiment.

\section{Materials and Methods}

Laboratory Experiment

Materials

36 soil samples of the unsaturated zone were collected from the study area in August 2014. The lithology is sub-clay, silty sand, medium-fine sand with gravel, and medium-coarse sand. A soil sampler (ETC-300A, China) was used to collect the soil samples from the unsaturated zone at $20 \mathrm{~cm}$ intervals from the surface. The collected samples were placed in a valve bag and sealed.

\section{Experimental Device and Filling of Soil Column}

The soil water and salt transport column experiment was carried out in an organic glass column with an inner diameter of $10 \mathrm{~cm}$ and a height of $1 \mathrm{~m}$. Sampling holes, at intervals of $5 \mathrm{~cm}$, were set up on the wall of the column (Fig. 3).

The simulated soil column was filled according to the natural dry density of the unsaturated zone (Table 1). Before the soil column was filled, it was necessary to calculate the quality of the required soil sample:

$$
M=V \times \rho_{d} /(1+1 / \theta)
$$

...where $M$ is the quality of each layer (M), $V$ is the volume of each layer $\left(\mathrm{L}^{3}\right), \rho_{d}$ is the natural dry density of the soil $\left(\mathrm{ML}^{-3}\right)$, and $\theta$ is the water content of the dry soil $\left(\mathrm{L}^{3} \mathrm{~L}^{-3}\right)$.

The soil columns were designed using the dimensional similarity theory, and were divided into groups A and B. The Group A soil column simulated the unsaturated zone with a thickness of $3.0 \mathrm{~m}$ in the shallow groundwater area, and was a 1:4 scaled-down model of the prototype. The silty sand layer at the bottom was saturated (simulating the phreatic aquifer) by water with a TDS of $2 \mathrm{~g} / \mathrm{L}$ (the TDS value of phreatic water in the study area). The Group B soil column simulated the unsaturated zone with a thickness of $13.5 \mathrm{~m}$ for the deep groundwater area, and was a 1:15 scaled-down model 
Table 2. Soil column experiment specifications.

\begin{tabular}{|c|c|c|c|c|c|}
\hline Number & $\begin{array}{l}\text { Irrigation methods and } \\
\text { volume }(\mathrm{mL})\end{array}$ & $\begin{array}{l}\text { Irrigation water } \\
\text { TDS }(\mathrm{g} / \mathrm{L})\end{array}$ & $\begin{array}{l}\text { Evaporation } \\
(13.28 \mathrm{~mm} / \mathrm{d})\end{array}$ & $\begin{array}{l}\text { Transpiration } \\
(5.5 \mathrm{~mm} / \mathrm{d})\end{array}$ & $\begin{array}{c}\text { Conversion of evaporation } \\
(\mathrm{mm} / \mathrm{d})\end{array}$ \\
\hline A-1 & \multirow{2}{*}{ Flood irrigation (1250) } & 3.0 & $\sqrt{ }$ & $\sqrt{ }$ & 4.70 \\
\hline A-2 & & 0.5 & $\sqrt{ }$ & $\sqrt{ }$ & 4.70 \\
\hline B-1 & \multirow{2}{*}{ Flood irrigation (333) } & 3.0 & $\sqrt{ }$ & $\sqrt{ }$ & 1.25 \\
\hline B-2 & & 0.5 & $\sqrt{ }$ & $\sqrt{ }$ & 1.25 \\
\hline B-3 & \multirow{2}{*}{$\begin{array}{l}\text { Drip irrigation under } \\
\text { plastic film (220) }\end{array}$} & 3.0 & & $\sqrt{ }$ & 0.37 \\
\hline B-4 & & 0.5 & & $\sqrt{ }$ & 0.37 \\
\hline
\end{tabular}

Note: The evaporation and transpiration rates set were the average values from June to August.

of the prototype. The B soil column was saturated from bottom to top by water with a TDS of $0.75 \mathrm{~g} / \mathrm{L}$ (the TDS value of tap water). After the soil column was saturated, gravity drainage was carried out for 3 days, and then the sampling hole at the bottom of the soil column was closed for 5 days to simulate the water content of the unsaturated zone under natural conditions.

\section{Experiment Design}

In the cotton-growing region of the study area, the irrigation methods are divided into flood and drip irrigation under plastic film. River water (TDS $0.5 \mathrm{~g} / \mathrm{L}$ ) is the irrigation water source in the irrigated area near the river, while confined water (TDS $3.0 \mathrm{~g} / \mathrm{L}$ ) is the irrigation water source in the irrigated area away from the river. Therefore, six experiments were designed to fully investigate the influence of irrigation method, irrigation water quality, and evaporation conditions, on soil water and salt transport. The scaling parameters used in the soil column experiment were calculated using Formula (2). The specifications for each experiment are shown in Table 2.

$$
\lambda=\frac{P}{F}
$$

...where $\lambda$ is the scale factor of the model (soil column experiment) and the prototype (the unsaturated zone in the field), $\lambda_{\text {group } \mathrm{A}}=4, \lambda_{\text {group } \mathrm{B}}=15 ; P$ is a prototype dimension; and $F$ is the model dimension (the volume of irrigation water and conversion of evaporation).

\section{Analytical Methods}

Before the experiment was started, the water content and electrical conductivity of the soil samples at different depths were measured. At the bottom of the soil column, a sampling hole was set up to measure the $\mathrm{Cl}^{-}, \mathrm{HCO}_{3}^{-}$, and TDS of the water samples.

After the experiment was started, the water content and electrical conductivity at different depths of the soil column were measured every 24 hours and monitored for 10 days (the irrigation period). In this experiment, three irrigation periods were simulated for 30 days. The instruments used are listed in Table 3. Formula (3) was used to convert the electrical conductivity of the soil water to TDS [9].

$$
T D S=0.6546 E C
$$

\section{Model Simulation}

\section{Mathematical Formulation for the Hydrus-1D Model}

The Richards equation [30] was used to describe soil-water flow:

$$
\frac{\partial \theta}{\partial t}=\frac{\partial}{\partial Z}\left[K\left(\frac{\partial h}{\partial Z}+1\right)\right]-S(Z, t)
$$

...where $\theta$ is the soil water content $\left(\mathrm{L}^{3} \mathrm{~L}^{-3}\right), \quad h$ is the pressure head $(\mathrm{L}), z$ is the vertical space coordinate (L), $t$ is time (T), $K$ is the hydraulic conductivity $\left(\mathrm{LT}^{-1}\right)$, and $\mathrm{S}$ is the sink or source term for water $\left(\mathrm{L}^{3} \mathrm{~L}^{-3} \mathrm{~T}^{-1}\right)$.

Table 3. Test index and instruments used in the experiments.

\begin{tabular}{|c|c|c|}
\hline Test index & Test instrument & Model \\
\hline Water content & Soil moisture meter & DH832, America \\
\hline Electrical conductivity & Soil electrical conductivity meter & HI98331, Italy \\
\hline $\mathrm{pH}, \mathrm{TDS}$ & Hanna & HI98130, Italy \\
\hline $\mathrm{Cl}^{-}$ & Ion chromatograph & 881 Compact IC pro, Switzerland \\
\hline
\end{tabular}


The van Genuchten-Mualem functional relationships [31-32] were used to describe the hydraulic properties of unsaturated soil:

$$
\begin{gathered}
\theta(h)=\left\{\begin{array}{cc}
\theta_{r}+\frac{\theta_{s}-\theta_{r}}{\left[1+|\alpha h|^{n}\right]^{m}} & h<0 \\
\theta_{s} & h \geq 0
\end{array}\right. \\
K(h)=K_{S} S_{e}^{l}\left[1-\left(1-S_{e}^{1 / m}\right)^{m}\right]^{2} \\
S_{e}=\frac{\theta-\theta_{r}}{\theta_{s}-\theta_{r}}
\end{gathered}
$$

...where $\theta_{r}$ and $\theta_{s}$ are the residual and saturated volumetric water content $\left(\mathrm{L}^{3} \mathrm{~L}^{-3}\right) ; \alpha\left(\mathrm{L}^{-1}\right)$ and $\mathrm{n}$ represent the empirical shape parameters, $m=1-1 / n$; $K_{s}$ is saturated hydraulic conductivity $\left(\mathrm{LT}^{-1}\right) ; 1$ is the pore connectivity parameter, which is taken as 0.5 [31]; and $S_{e}$ is the effective saturation.

The convection-diffusion equation [30] was used to describe salt transport in the homogeneous one-dimensional porous medium:

$$
\frac{\partial \theta c}{\partial t}=\frac{\partial}{\partial z}\left(\theta D \frac{\partial c}{\partial z}\right)-\frac{\partial q c}{\partial z}-\varphi
$$

...where $\quad c$ is the solute concentration $\left(\mathrm{ML}^{-3}\right), D$ is the dispersion coefficient $\left(\mathrm{L}^{2} \mathrm{~T}^{-1}\right), \varphi$ is a sink or a source for solutes $\left(\mathrm{ML}^{-3} \mathrm{~T}^{-1}\right)$, and $q$ is the volumetric flux density given by Darcy's law $\left(\mathrm{LT}^{-1}\right)$.

The actual root water uptake is obtained from the potential root water uptake by multiplication with a stress response function [33] that accounts for water stress:

$$
S(h)=\alpha(h) S_{p}
$$

...where $S_{p}$ and $S(h)$ are the potential and actual volumes of water removed from a unit volume of soil per unit time $\left(\mathrm{L}^{3} \mathrm{~L}^{-3} \mathrm{~T}^{-1}\right)$, and $\alpha(h)$ is a dimensionless function of the soil water and osmotic pressure heads $(0 \leq \alpha \leq 1)$.

Root water uptake caused by water stress was described using the model introduced by Feddes [34]:

$$
\alpha(h)=\left\{\begin{array}{cl}
\frac{h_{1}-h}{h_{1}-h_{2}} & h_{2}<h \leq h_{1} \\
\frac{h-h_{4}}{h_{3}-h_{4}} & h_{4}<h \leq h_{3} \\
1 & h_{3}<h \leq h_{2} \\
0 & h>h_{1}, h \leq h_{4}(10)
\end{array}\right.
$$

...where $h_{1}, h_{2}, h_{3}$, and $h_{4}$ are the threshold parameters. Water uptake is at the potential rate when the pressure head is between $h_{2}$ and $h_{3}$, drops off linearly when $h>h_{2}$ or $h<h_{3}$, and becomes zero when $h<h_{4}$ or $h>h_{l}$.

\section{Initial and Boundary Conditions in the Column}

The initial and boundary conditions of soil water movement were described as follows:

$$
\begin{gathered}
\theta(z, 0)=\theta_{i}(z) \quad-Z \leq z \leq 0 \\
-K(h)\left(\frac{\partial h}{\partial z}+1\right)=q_{s}=\left\{\begin{array}{c}
R(t) \\
-E(t)
\end{array} \quad z=0\right. \\
h(Z, t)=h_{b}(t) \quad Z=-75 \mathrm{~cm}(A) ; Z=-90 \mathrm{~cm}(B)
\end{gathered}
$$

... where $\theta_{i}(\mathrm{z})$ is the initial soil water content, $q_{s}$ is the vertical water exchange intensity of the upper boundary $\left(\mathrm{LT}^{-1}\right)$, and $h_{b}(t)$ is the pressure head of the lower boundary (L).

The initial and boundary conditions of solute transport were described as follows:

$$
\begin{gathered}
c(z, 0)=c_{0}(z) \quad-Z \leq z \leq 0, t=0 \\
-\theta D \frac{\partial c}{\partial z}+q c=q_{s} c_{s}(t) \quad z=0, t>0 \\
c(Z, t)=c_{b}(t) \quad Z=-75 \mathrm{~cm}(A) ; Z=-90 \mathrm{~cm}(B), t>0
\end{gathered}
$$

$\ldots$ where $C_{0}(z)$ is the initial soil water $\operatorname{TDS}\left(\mathrm{ML}^{-3}\right), \mathrm{C}_{s}$ is the TDS concentration of irrigation water $\left(\mathrm{ML}^{-3}\right)$, and $\mathrm{C}_{\mathrm{b}}$ is the TDS concentration of the lower boundary $\left(\mathrm{ML}^{-3}\right)$

Table 4. Initial hydraulic parameters of Hydrus-1D model.

\begin{tabular}{|c|c|c|c|c|c|c|}
\hline Lithology & $\begin{array}{c}\boldsymbol{\theta}_{\mathrm{r}} \\
\left(\mathrm{m}^{3} \mathrm{~m}^{-3}\right)\end{array}$ & $\begin{array}{c}\boldsymbol{\theta}_{\mathrm{s}} \\
\left(\mathrm{m}^{3} \mathrm{~m}^{-3}\right)\end{array}$ & $\begin{array}{c}\boldsymbol{\alpha} \\
(1 / \mathrm{cm})\end{array}$ & $\mathrm{n}$ & $\begin{array}{c}\mathrm{K}_{\mathrm{s}} \\
(\mathrm{m} / \mathrm{d})\end{array}$ & $\begin{array}{c}\text { Dispersivity } \\
(\mathrm{cm})\end{array}$ \\
\hline Sub-clay & 0.0334 & 0.3335 & 0.0111 & 1.5193 & 0.3092 & 4.24 \\
\hline Silty sand & 0.0391 & 0.3925 & 0.0433 & 1.8239 & 1.6179 & 0.7648 \\
\hline Medium-fine sand with gravel & 0 & 0.35 & 0.1 & 2.5 & 10 & 2.7557 \\
\hline Medium-coarse sand & 0 & 0.35 & 0.12 & 3 & 30 & 5.89 \\
\hline
\end{tabular}


Table 5. Root water uptake parameters in the Feddes water stress response model.

\begin{tabular}{|c|c|c|c|c|}
\hline $\mathrm{h}_{1}(\mathrm{~cm})$ & $\mathrm{h}_{2}(\mathrm{~cm})$ & $\mathrm{h}_{3 \text { high }}(\mathrm{cm})$ & $\mathrm{h}_{3 \text { low }}(\mathrm{cm})$ & $\mathrm{h}_{4}(\mathrm{~cm})$ \\
\hline-10 & -25 & -200 & -600 & -14000 \\
\hline
\end{tabular}

\section{Input Parameters}

In this study, the initial hydraulic parameters for the soil were based on previous research findings of the study area [23].

The dispersivity was obtained from the four groups of one-dimensional dispersion experiments (the tracer is a $100 \mathrm{mg} / \mathrm{L} \mathrm{NaBr}$ solution) with the four kinds of media (Table 4).

\section{Calibration and Validation of the Hydrus-1D Model}

The Hydrus-1D model was calibrated using the data from the first two irrigation periods. The parameter optimization module (inverse modeling) incorporated in HYDRUS-1D was employed to optimize $\theta_{\mathrm{r}}, \theta_{\mathrm{s}} \alpha, \mathrm{n}$, $\mathrm{K}_{\mathrm{s}}$ and dispersivity simultaneously using the observed data, initial conditions, initial estimates, and boundary conditions. One parameter at a time was optimized for each layer, the remaining parameters being kept fixed. This procedure was repeated for each parameter. Then the model was validated with the observed data from the third irrigation period without changing the calibrated parameters.

The root mean square error (RMSE) and coefficient of determination $\left(\mathrm{R}^{2}\right)$ were used to evaluate the agreement between the predicted and observed data.

$$
\begin{aligned}
& R M S E=\sqrt{\frac{\sum_{i=1}^{n}\left(P_{i}-O_{i}\right)^{2}}{n}} \\
& R^{2}=1-\frac{\sum_{i=1}^{n}\left(P_{i}-O_{i}\right)^{2}}{\sum_{i=1}^{n}\left(O_{i}-\bar{O}\right)^{2}}
\end{aligned}
$$

...where $P_{i}$ and $O_{i}$ are the values of observed and predicted values, $\bar{O}$ is the average of observed values, and $\mathrm{n}$ is the number of observations.

\section{Model Prediction}

The soil column experiment replicates the real-world unsaturated zone. Samples taken from the base of the column are therefore equivalent to water moving from the unsaturated zone to the phreatic zone. Thus, results from the column experiment can be used to make predictions regarding real-world groundwater quality.

In this study, the Hydrus-1D model was used to predict soil water and salt transport for different lithological structures and irrigation water quality, and to reveal the impact of long-term irrigation on groundwater quality.

\section{Initial and Boundary Conditions in the Field}

After considering the water uptake of the roots, the initial and boundary conditions of soil water movement were adjusted as follows:

$$
\begin{gathered}
\theta(z, 0)=\theta_{i}(z) \quad-Z \leq z \leq 0 \\
-K(h)\left(\frac{\partial h}{\partial z}+1\right)=q_{s} \\
h(Z, t)=h_{b}(t) \quad Z=-300 \mathrm{~cm}(A) ; Z=-1350 \mathrm{~cm}(B)
\end{gathered}
$$

The initial and boundary conditions of solute transport were adjusted as follows:

Table 6. Potential evapotranspiration reference values

\begin{tabular}{|c|c|c|c|c|c|c|c|c|c|c|c|c|}
\hline Month & Jan & Feb & Mar & Apr & May & Jun & Jul & Aug & Sep & Oct & Nov & Dec \\
\hline $\mathrm{ET}_{\mathrm{p}}(\mathrm{mm} / \mathrm{d})$ & 0.33 & 0.78 & 2.34 & 4.51 & 5.69 & 5.92 & 5.47 & 4.98 & 4.13 & 2.25 & 0.83 & 0.30 \\
\hline
\end{tabular}

Table 7. Predicted scenarios.

\begin{tabular}{|c|c|c|c|c|c|c|c|c|c|c|c|c|c|}
\hline Group & \multicolumn{7}{|c|}{$\mathrm{A}$} & \multicolumn{1}{|c|}{ B } \\
\hline Scheme & 1 & 2 & 3 & 4 & 5 & 6 & 7 & 8 & 9 & 10 & 11 & 12 \\
\hline Irrigation water TDS $(\mathrm{g} / \mathrm{L})$ & 3 & 2.5 & 2 & 1.5 & 1 & 0.5 & 3 & 2.5 & 2 & 1.5 & 1 & 0.5 \\
\hline Irrigation time & \multicolumn{7}{|c|}{ Jarch $15^{\text {th }} ;$ June $15^{\text {th }}, 25^{\text {th }} ;$ July $5^{\text {th }}, 15^{\text {th }}, 25^{\text {th }} ;$ August $15^{\text {th }}$} \\
\hline Growth periods of cotton & \multicolumn{7}{|c|}{ Flooding $(0.6)$} \\
\hline Irrigation methods and volume $\left(\mathrm{m}^{3} / \mathrm{m}^{2}\right)$ & \multicolumn{10}{|c|}{} \\
\hline
\end{tabular}




$$
\begin{gathered}
c(z, 0)=c_{0}(z) \quad-Z \leq z \leq 0, t=0 \\
-\theta D \frac{\partial c}{\partial z}+q_{z} c=q_{s} c_{s}(t) \quad z=0, t>0 \\
c(Z, t)=c_{b}(t) \quad Z=-300 \mathrm{~cm}(A) ; Z=-1350 \mathrm{~cm}(B), t>0
\end{gathered}
$$

\section{Determining Model Parameters}

The Feddes model parameters (Table 5) were synthesized based on the method of Wang and Forkutsa $[9,35]$.

Potential evapotranspiration $\left(\mathrm{ET}_{\mathrm{p}}\right)$ was divided into potential evaporation $\left(\mathrm{E}_{\mathrm{p}}\right)$ and potential transpiration $\left(\mathrm{T}_{\mathrm{p}}\right)$ according to Beer's Law [35]. The values of $\mathrm{ET}_{\mathrm{p}}$ are shown in Table 6.

$$
\begin{array}{r}
E_{p}(\mathrm{t})=E T_{p}(t) \cdot e^{-\beta \cdot L A I(t)} \\
T_{p}(t)=E T_{p}(t)-\mathrm{E}_{p}(t)
\end{array}
$$

...where $L A I$ is the leaf area index $\left(L A I=5.5+1.5 \ln \left(h_{c}\right)\right.$, $h_{c}$ is the height of the crop (L)), and $\beta$ is the extinction coefficient (assumed to be 5).

The climate in the field is arid and the precipitation is low. Therefore, in the model, the study area was set to rain twice a month (on the 10th and 20th of each month), and the precipitation was half of the average monthly rainfall. Referring to measured data, The TDS of the rainfall was set at $0.2 \mathrm{~g} / \mathrm{L}$.

\section{Predicted Scenarios}

To predict the impact of long-term irrigation on groundwater quality, 12 scenarios were set in the Hydrus-1D model (Table 7).

The start time of the simulation was set at June $15^{\text {th }}$. The variation in soil water TDS at the bottom of the unsaturated zone was predicted for a time period of 5 years.

\section{Results and Discussion}

\section{Water Content Variation in the Soil Column}

The variations in soil water content at different depths in the soil columns (with the same irrigation water quality) during three irrigation periods were analyzed to investigate the influence of the lithological structures of the unsaturated zone, irrigation methods, and volume on soil water transport. The results are shown in Fig. 4.

The soil water content at the depth of $5 \mathrm{~cm}$ (sub-clay layer) presents periodic variation (by a cycle of 10 days, one irrigation period) with time (Fig. 4). On the first day of each irrigation period, the soil water content at the depth of $5 \mathrm{~cm}$ (sub-clay layer) was close to saturation. Subsequently, under the influence of infiltration and strong evaporation, the soil water content began to decrease. The water content exhibited by the topsoil in this study is consistent with findings of Xie and Chen [36-37]. The variation trends for soil water content at a depth of $5 \mathrm{~cm}$ (sub-clay layer) and $20 \mathrm{~cm}$ (silty sand layer) in the A-1 column were consistent, and the maximum value for soil water content was observed on the first day of each irrigation period. Because the subclay layer in the B-1 column is thick, the infiltration rate for irrigation water is small, and the variation of

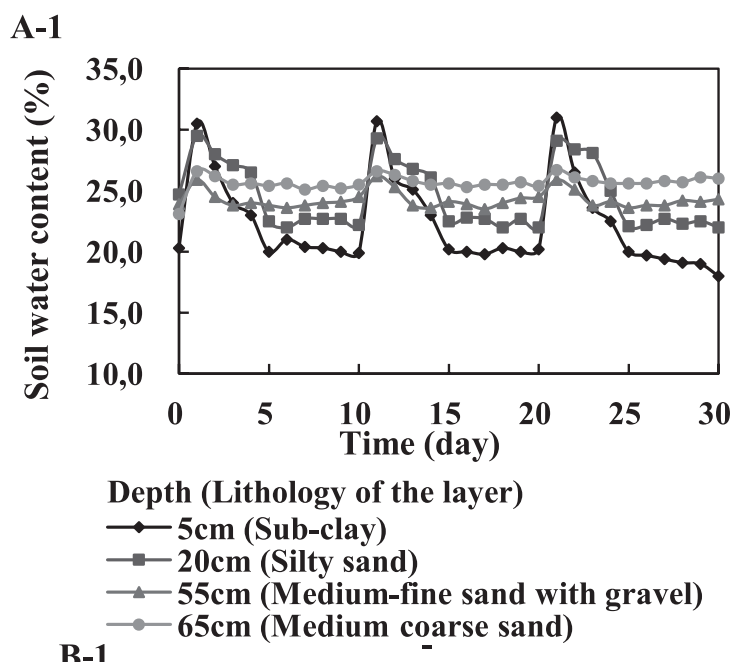

B-1

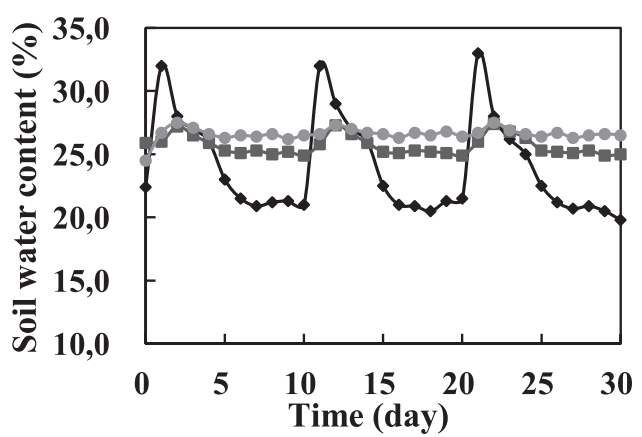

Depth (Lithology of the layer)

$$
\begin{aligned}
& \longrightarrow-5 \mathrm{~cm} \text { (Sub-clay) } \\
& \longrightarrow-35 \mathrm{~cm} \text { (Silty sand) } \\
& \because-85 \mathrm{~cm} \text { (Silty sand) }
\end{aligned}
$$

B-3

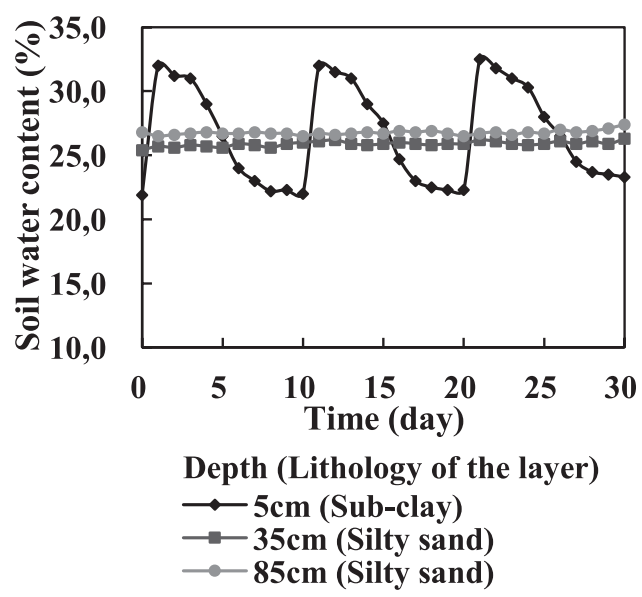

Fig. 4. Variation in soil water content at different depths in the A-1, B-1, and B-3 soil columns. 
soil water content at depths of $35 \mathrm{~cm}$ and $85 \mathrm{~cm}$ (silty sand layer) has a noticeable lag, compared with that at the depth of $5 \mathrm{~cm}$ (sub-clay layer). Similar results were concluded in the previous studies [38-41]. In the B-1 column, the maximum soil water content occurs on the second day of each irrigation period. In the B-3 column, the soil water content at the depth of $5 \mathrm{~cm}$ (sub-clay layer) is larger during the first three days of each irrigation period, which is related to the drip irrigation. There was no significant change in water content at depths of $35 \mathrm{~cm}$ and $85 \mathrm{~cm}$ (silty sand layer) in the B-3 column during the irrigation periods because of the small infiltration rate for drip irrigation.

\section{Salt Content Variation in the Soil Column}

The variations of the soil water TDS at different depths in the soil columns (according to the irrigation a)

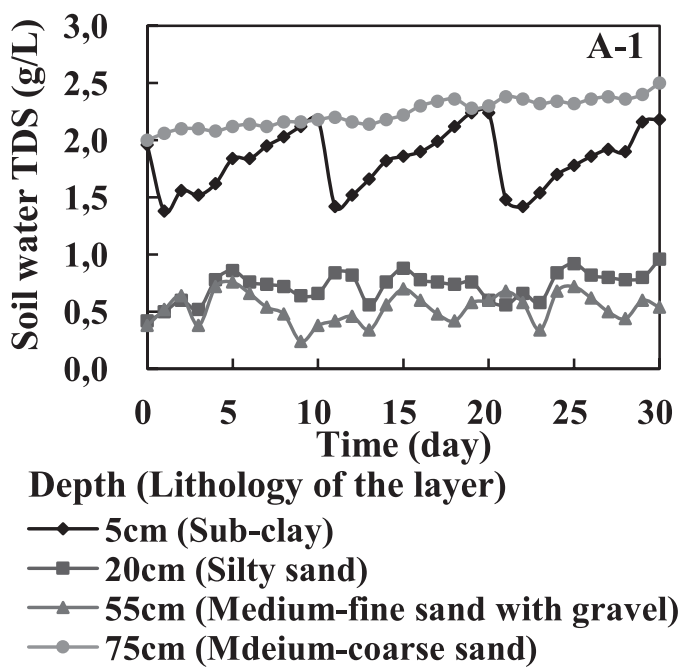

c)

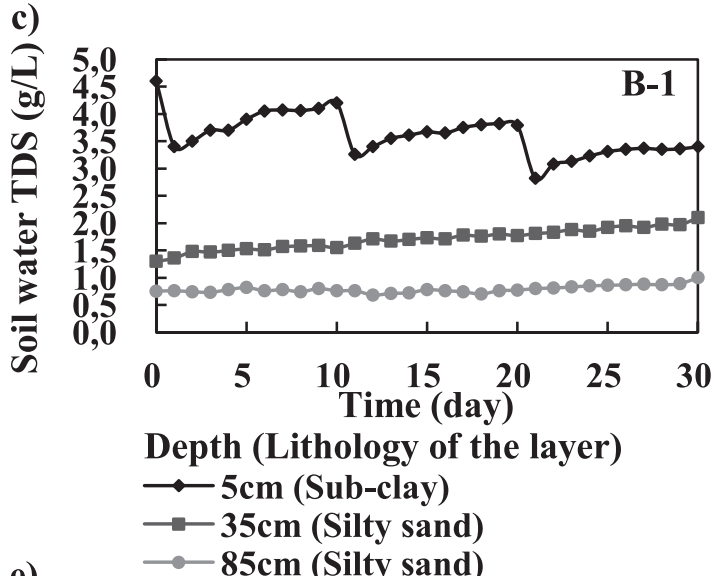

e) $\quad-85 \mathrm{~cm}$ (Silty sand)

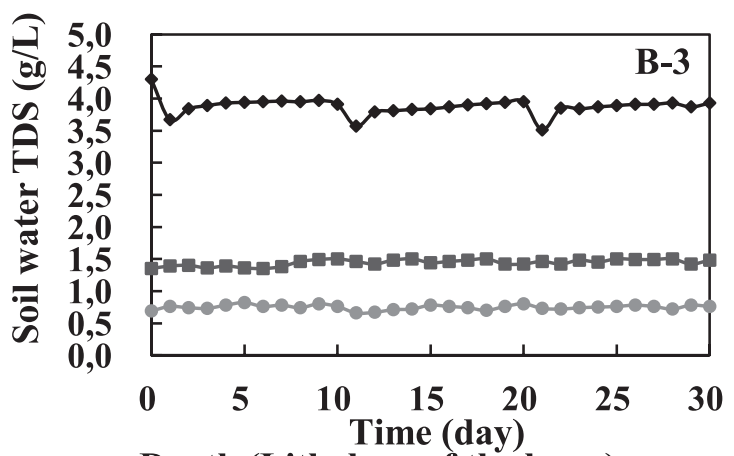

Depth (Lithology of the layer)

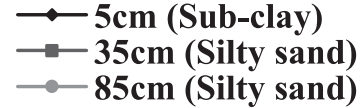

b)

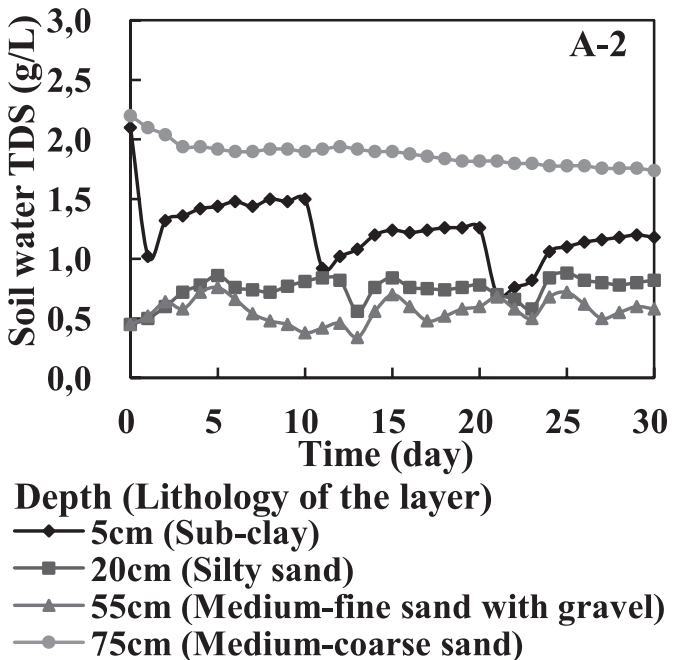

d)

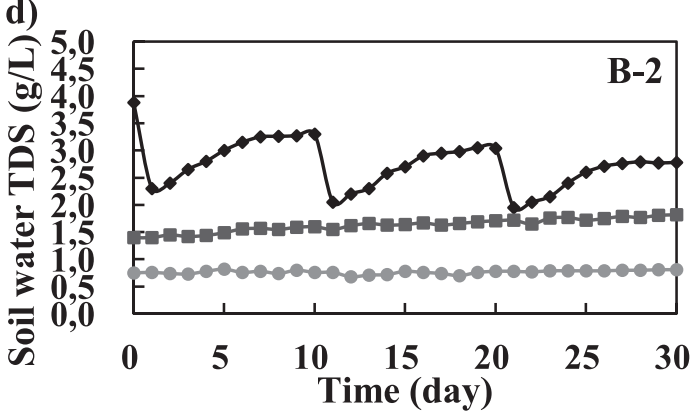

Depth (Lithology of the layer)

$\longrightarrow-5 \mathrm{~cm}$ (Sub-clay)

$\longrightarrow-35 \mathrm{~cm}$ (Silty sand)

f)

$85 \mathrm{~cm}$ (Silty sand)

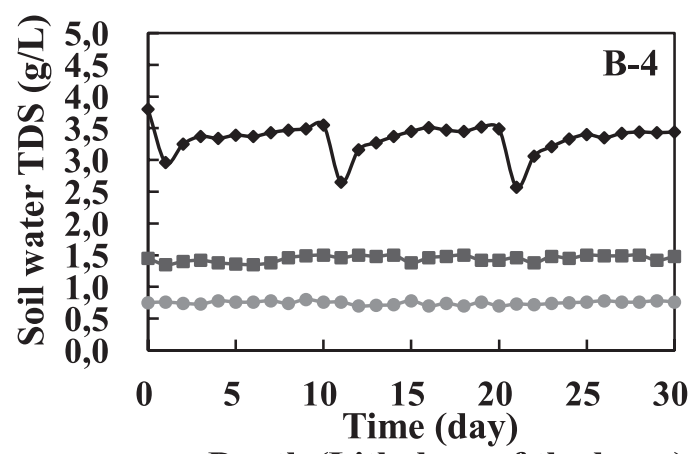

Depth (Lithology of the layer)

$\longrightarrow-5 \mathrm{~cm}$ (Sub-clay)

$85 \mathrm{~cm}$ (Silty sand)

Fig. 5. Variations of the soil water TDS at different depths in the soil columns. 
water volume, experiments of six soil columns were divided into three groups for analysis) during three irrigation periods were analyzed to investigate the influence of the lithological structures of the unsaturated zone, water quality, and methods of irrigation on salt transport (Fig. 5).

Soil water TDS at a depth of $5 \mathrm{~cm}$ (sub-clay layer) presents periodic variation (by a cycle of 10 days, one irrigation period) with time (Fig. 5a, b). On the first day of each irrigation period, the salt in the shallow layer of the unsaturated zone moved downward with the irrigation water. Subsequently, under the influence of strong evaporation, the soil water TDS at a depth of $5 \mathrm{~cm}$ began to increase. This is consistent with the results of the study by Gen and Wang [42-43]. During the irrigation periods, the variation in soil water TDS at the depth of $5 \mathrm{~cm}$ (sub-clay layer) and the groundwater TDS at a depth of $75 \mathrm{~cm}$ showed an increasing trend in the A-1 column when irrigation with water of high TDS was carried out. In comparison, the variation in soil water TDS at a depth of $5 \mathrm{~cm}$ (sub-clay layer) and the groundwater TDS at a depth of $75 \mathrm{~cm}$ showed a decreasing trend in the A-2 column when irrigation with water of low TDS was carried out. The results showed that irrigation water with a high TDS had a large influence on salt deposition at soil surfaces, and on groundwater salinization in the case of thin and highly permeable layers. Several investigators had also demonstrated similar results [44-45].

Soil water TDS at a depth of $5 \mathrm{~cm}$ (sub-clay layer) presents periodic variation (by a cycle of 10 days, one irrigation period) with time (Fig. 5c, d). During the irrigation periods, the variation in soil water TDS at a depth of $5 \mathrm{~cm}$ (sub-clay layer) showed a decreasing trend when irrigation with water of low TDS was carried out, while groundwater TDS at a depth of $85 \mathrm{~cm}$ remained constant. The results showed that either the irrigation water did not readily affect the groundwater quality, or that this process is slower in the case of thick and low permeable layers.

Soil water TDS at a depth of $5 \mathrm{~cm}$ (sub-clay layer) presents periodic variation (by a cycle of 10 days, one irrigation period) with time, but the amplitude of variations is small, which indicated that the effect of salt-leaching is weak for drip irrigation (Fig. 5e, f). There were no significant changes in the soil water TDS at a depth of $85 \mathrm{~cm}$ (silty sand layer) in the B-3 and B-4 columns during the irrigation periods.

\section{Model Calibration and Validation}

Based on the laboratory soil column experiments, it can be concluded that groundwater quality is not readily affected by irrigation water, and that the effect
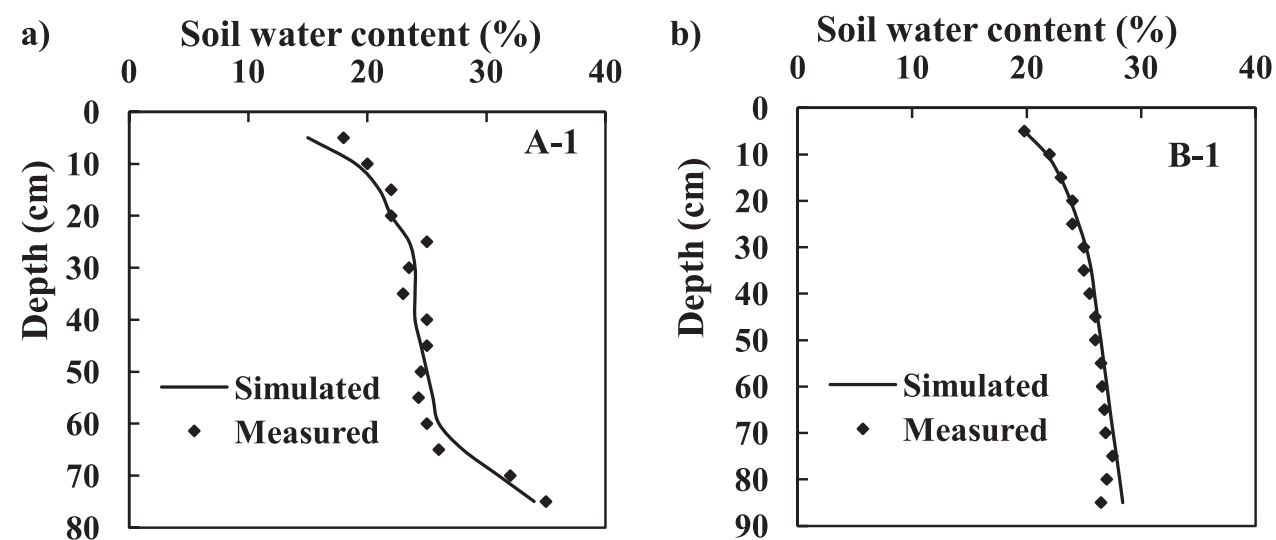

c)

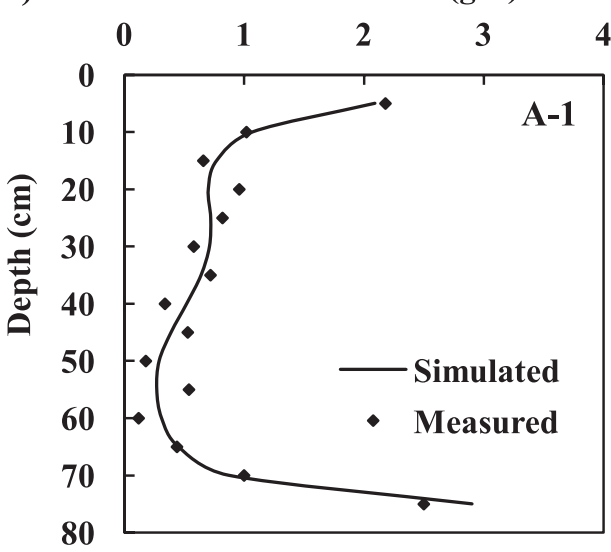

d)

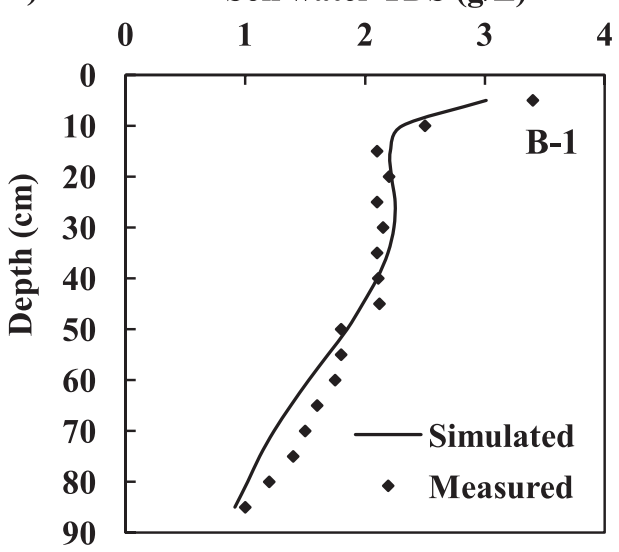

Fig. 6. Measured and simulated values at different soil column depths during the validation period. 
Table 8. Calibrated parameters of Hydrus-1D model.

\begin{tabular}{|c|c|c|c|c|c|c|}
\hline Lithology & $\begin{array}{c}\theta_{\mathrm{r}} \\
\left(\mathrm{m}^{3} \mathrm{~m}^{-3}\right)\end{array}$ & $\begin{array}{c}\theta_{\mathrm{s}} \\
\left(\mathrm{m}^{3} \mathrm{~m}^{-3}\right)\end{array}$ & $\begin{array}{c}\alpha \\
(1 / \mathrm{cm})\end{array}$ & $\mathrm{n}$ & $\begin{array}{c}\mathrm{K}_{\mathrm{s}} \\
(\mathrm{m} / \mathrm{d})\end{array}$ & $\begin{array}{c}\text { Dispersivity } \\
(\mathrm{cm})\end{array}$ \\
\hline Sub-clay & 0.0334 & 0.3335 & 0.0098 & 1.38 & 0.2 & 4.24 \\
\hline Silty sand & 0.0391 & 0.3925 & 0.0412 & 1.25 & 2 & 2.4 \\
\hline Medium-fine sand with gravel & 0 & 0.35 & 0.013 & 2.11 & 10 & 10 \\
\hline Medium-coarse sand & 0 & 0.35 & 0.015 & 2.3 & 30 & 20 \\
\hline
\end{tabular}

of salt-leaching on the unsaturated zone is minimal for drip irrigation, and for thick sub-clay layer with small infiltration rates. Therefore, in this study, soil water and salt transport of the A-1 and B-1 soil columns were simulated and predicted under flood irrigation conditions.

\section{Water Transport in Unsaturated Zone during Irrigation}

On the $30^{\text {th }}$ day of the A-1 and B-1 soil columns (Fig. 6a, b), the simulated values for the TDS of the soil water were in good agreement with the measured values $\left(R M S E_{\mathrm{A}-1}=1.276 \mathrm{~cm}^{3} \mathrm{~cm}^{-3}, R_{\mathrm{A}-1}^{2}=0.901\right.$, $R M S E_{\mathrm{B}-1}=0.657 \mathrm{~cm}^{3} \mathrm{~cm}^{-3}$, and $\left.R_{\mathrm{B}-1}^{2}=0.893\right)$. This indicates that the model parameters are realistic and that water movement in the unsaturated zone can be accurately simulated. The calibrated conductive parameters for soil water are shown in Table 8.

\section{Salt Transport in Unsaturated Zone during Irrigation}

On the 30th day of the A-1 and B-1 soil columns (Fig. 6c, d), the simulated values of soil water content were in good agreement with the measured values $\left(R M S E_{\mathrm{A}-1}=0.178 \mathrm{gL}^{-1}, \quad R^{2}{ }_{\mathrm{A}-1}=0.925\right.$, $R M S E_{\mathrm{B}-1}=0.181 \mathrm{gL}^{-1}$, and $\left.R_{\mathrm{B}-1}^{2}=0.883\right)$. This indicates that the parameters of the model are realistic and the salt transport in the unsaturated zone can be accurately simulated. The values for dispersivity in the model of A-1 column were set using trial and error. The values of dispersivity in the model of the B-1 column were adjusted to $1 \%$ of the observation scale in the field by taking into account the scale effect of dispersivity [46]. The calibrated salt transport parameters are shown in Table 8.

\section{Prediction under Different Scenarios}

The validated soil column model was used to study and predict the influence of soil water and salt transport on groundwater quality in the study area when flood irrigation was carried out.

\section{Unsaturated Zone in the Shallow Groundwater Area (Group A)}

This scenario involved a coarse-grained unsaturated zone with a small thickness $(3.0 \mathrm{~m})$. The changes in the TDS of soil water at the bottom of the unsaturated zone $(3.0 \mathrm{~m})$ after 5 years are shown in Fig. 7 for

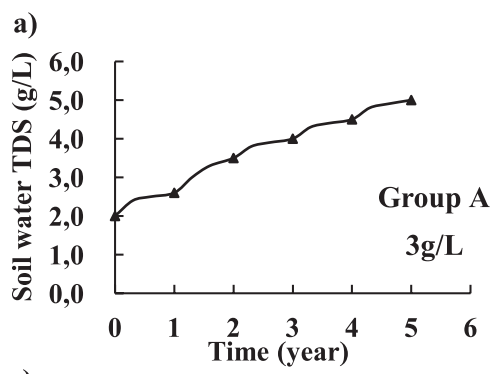

b)
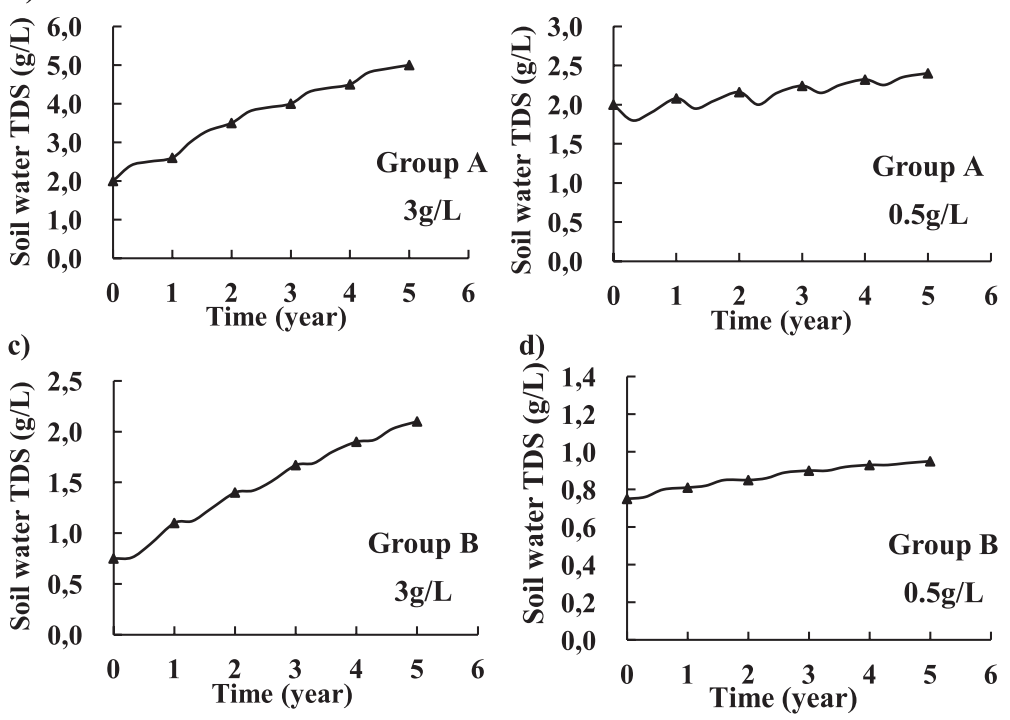

Fig. 7. Changes in the TDS of soil water at the bottom of the unsaturated zone for long-term irrigation. 

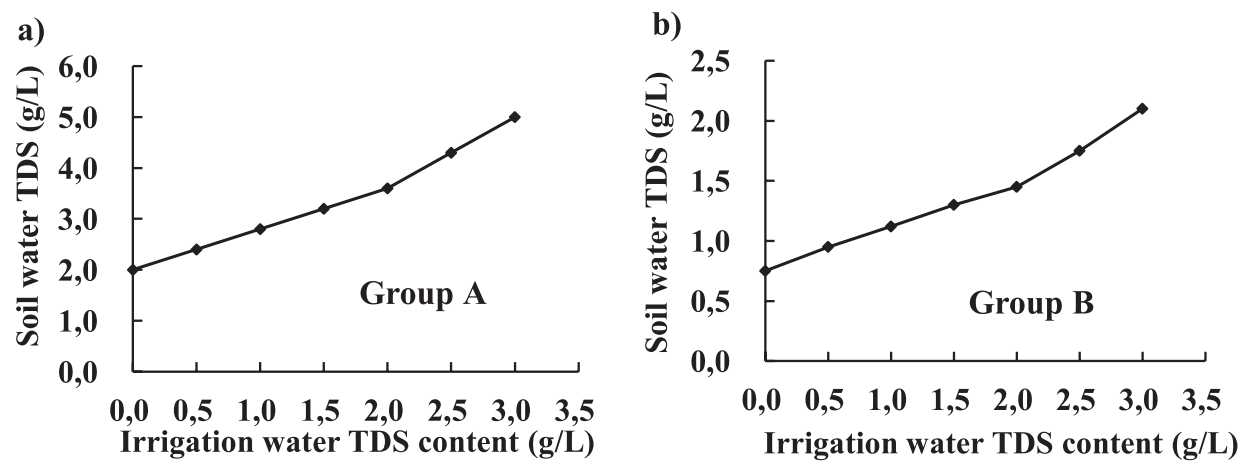

Fig. 8. Soil water TDS at the bottom of the unsaturated zone versus irrigation water TDS.

irrigation water with a TDS of $3 \mathrm{~g} / \mathrm{L}$ (confined water) and $0.5 \mathrm{~g} / \mathrm{L}$ (river water).

The variation in the TDS of soil water at the bottom of the unsaturated zone showed a periodic annual change trend (Fig. 7a, b). The TDS of the soil water increased when irrigation water with a relatively large $(3 \mathrm{~g} / \mathrm{L})$ and small $(0.5 \mathrm{~g} / \mathrm{L})$ TDS was applied. Irrigation water with a TDS of $3 \mathrm{~g} / \mathrm{L}$ had a greater impact on groundwater salinization. This is consistent with previous studies [47-48]. The TDS of soil water increased from $2.0 \mathrm{~g} / \mathrm{L}$ to about $5.0 \mathrm{~g} / \mathrm{L}$ after 5 years of irrigation using water with a TDS of $3 \mathrm{~g} / \mathrm{L}$, and the amplitude of variation was large. In contrast, the TDS of soil water increased from $2.0 \mathrm{~g} / \mathrm{L}$ to about $2.5 \mathrm{~g} / \mathrm{L}$ after 5 years of irrigation using water with a TDS of $0.5 \mathrm{~g} / \mathrm{L}$, and the amplitude of variation was relatively small.

The relationship between irrigation water TDS and soil water TDS at the bottom of the unsaturated zone (3.0m) after 5 years of irrigation is shown in Fig. 8 .

Long-term irrigation had a large influence on soil water TDS at the bottom of the unsaturated zone in the shallow groundwater area (Fig. 8a). The soil water TDS, which was closely related to groundwater quality, increased as the irrigation water TDS increased. Moreover, when the irrigation water TDS was more than $2 \mathrm{~g} / \mathrm{L}$, the influence of long-term irrigation on groundwater salinization was more obvious.

\section{Unsaturated Zone in the Deep Groundwater Area (Group B)}

This scenario involved a fine-grained unsaturated zone with a large thickness $(13.5 \mathrm{~m})$. The changes in soil water TDS at the bottom of the unsaturated zone $(13.5 \mathrm{~m})$ after 5 years are shown in Fig. 7 for irrigation water with a TDS of $3 \mathrm{~g} / \mathrm{L}$ (confined water) and $0.5 \mathrm{~g} / \mathrm{L}$ (river water).

Long-term leaching with irrigation water of high TDS induced some of the salt from the unsaturated zone to enter the phreatic zone in the deep groundwater area, and increased the soil water TDS at the bottom of the unsaturated zone (Fig. 7c, d). The soil water TDS increased from $0.75 \mathrm{~g} / \mathrm{L}$ to about $2 \mathrm{~g} / \mathrm{L}$ after 5 years of irrigation using water with a TDS of $3 \mathrm{~g} / \mathrm{L}$, and the amplitude of variation was relatively large. In comparison, the soil water TDS increased from $0.75 \mathrm{~g} / \mathrm{L}$ to about $1 \mathrm{~g} / \mathrm{L}$ after 5 years of irrigation using water with a TDS of $0.5 \mathrm{~g} / \mathrm{L}$, and the amplitude of variation was relatively small.

The relationship between irrigation water TDS and soil water TDS at the bottom of the unsaturated zone after 5 years of irrigation is shown in Fig. 8.

Long-term irrigation had a large influence on the soil water TDS at the bottom of the unsaturated zone in the deep groundwater area (Fig. 8b). The soil water TDS, which was closely related to groundwater quality, increased as the irrigation water TDS increased. Moreover, when the irrigation water TDS was more than $2 \mathrm{~g} / \mathrm{L}$, the influence of long-term irrigation on groundwater salinization was more obvious.

\section{Conclusions}

Soil column experiments were carried out to investigate the influence of the lithological structures of the unsaturated zone, water quality, and methods of irrigation on soil water and salt transport in the Kongque River region. The results showed that for a thin and highly permeable layer, high TDS irrigation water had a large influence on salt deposition at the soil surface and on groundwater salinization. In contrast, when a thick and low permeability layer was tested, irrigation water quality did not readily affect groundwater quality. The salt-leaching effect is weak for drip irrigation.

Based on the results of laboratory soil column experiments, a one-dimensional model of soil water and salt transport was established using the Hydrus1D model. The results showed that groundwater TDS will increase depending on different conditions, and groundwater quality was significantly affected when irrigation water TDS was more than $2 \mathrm{~g} / \mathrm{L}$.

The influence of long-term irrigation on groundwater quality is smaller when drip irrigation is used. Drip irrigation can save water and should be promoted. The influence of irrigation on groundwater quality is larger when flood irrigation is used. Therefore, if flood irrigation cannot be avoided, it is recommended 
that irrigation water with a TDS below $2 \mathrm{~g} / \mathrm{L}$ should be used.

\section{Acknowledgements}

This work was supported by the National Key R\&D Program of China (grant number, 2017YFC0404600). We wish to thank Ming Bai and Lin Xie of the Xinjiang Bureau of Geology and Mineral Resources for their assistance in the field work. We also appreciate the anonymous reviewers and the editor of this paper.

\section{Conflict of Interest}

The authors declare no conflict of interest.

\section{References}

1. RAMOS T.B., SIMUNEK J., GONCALVES M.C., MARTINS J.C., PRAZERES A., CASTANHEIRA N.L. Field evaluation of a multicomponent solute transport model in soils irrigated with saline waters. Journal of Hydrology, 407 (1), 129, 2011.

2. RAHMAN M.M., HAGARE D., MAHESHWARI B., DILLON P. Impacts of prolonged drought on salt accumulation in the root zone due to recycled water irrigation. Water, Air, \& Soil Pollution, 226 (4), 1, 2015.

3. REN D., XU X., HAO Y., HUANG G. Modeling and assessing field irrigation water use in a canal system of hetao, upper yellow river basin: application to maize, sunflower and watermelon. Journal of Hydrology, 532, 122, 2016.

4. SHANG F.Z., REN S.M., YANG P.L., LI C.S., XUE Y.D., HUANG L.M. Modeling the risk of the salt for polluting groundwater irrigation with recycled water and ground water using hydrus-1 d. Water, Air, \& Soil Pollution, 227 (6), 1, 2016.

5. KANZARI S., HACHICHA M., BOUHLILA R., BATTLE-SALES J. Characterization and modeling of water movement and salts transfer in a semi-arid region of Tunisia (bou hajla, kairouan) - salinization risk of soils and aquifers. Computers \& Electronics in Agriculture, 86, 34, 2011.

6. TEDESCHI A., DELL A.R. Effects of irrigation with saline waters, at different concentrations, on soil physical and chemical characteristics. Agricultural Water Management, 77 (1), 308, 2005.

7. ABUSHARAR T.M., SALAMEH A.S. Reductions in hydraulic conductivity and infiltration rate in relation to aggregate stability and irrigation water turbidity. Agricultural Water Management, 29 (1), 53, 1995.

8. KANZARI S., HACHICHA M., BOUHLILA R., BATTLE-SALES J. Simulation of water and salts dynamics in Bouhajla (Central Tunisia): exceptional rainfall effect. Soil and Water Research, 7 (1), 36, 2012.

9. FORKUTSA I., SOMMER R., SHIROKOVA Y.I., LAMERS J.P.A, KIENZLER K., TISCHBEIN B. Modeling irrigated cotton with shallow groundwater in the aral sea basin of Uzbekistan: ii. soil salinity dynamics. Irrigation Science, 27 (4), 319, 2009.

10. ZENG W.Z., XU C., WU J.W., HUANG J.S. Soil salt leaching under different irrigation regimes: hydrus-1d modelling and analysis. Journal of Arid Land, 6 (1), 44, 2014.

11. ZHU Y.H., REN L.L., SKAGGS T.H., LV H.S., YU Z.B., WU Y.Q., FANG X.Q. Simulation of populus euphratica, root uptake of groundwater in an arid woodland of the Ejina basin, China. Hydrological Processes, 23 (17), 2460, 2009.

12. 12. ASKRI B., AHMED A.T., ABICHOU T., BOUHLILA R. Effects of shallow water table, salinity and frequency of irrigation water on the date palm water use. Journal of Hydrology, 513, 81, 2014.

13. 13. SULEIMAN A.A. Modeling daily soil water dynamics during vertical drainage using the incoming flow concept. Catena, 73 (3), 312, 2008.

14. SIMUNEK J., GENUCHTEN M.T.V., SEJNA M. Development and applications of the hydrus and stanmod software packages and related codes. Vadose Zone Journal, 7 (9), 587, 2008.

15. CHEN W.P., HOU Z.N., WU L.S., LIANG Y.C., WEI C.Z., YANG J.S. Evaluating salinity distribution in soil irrigated with saline water in arid regions of northwest china. Agricultural Water Management, 97 (12), 2001, 2010.

16. SHOUSE P.J., AYARS J.E., SIMUNEK J. Simulating root water uptake from a shallow saline groundwater resource. Agricultural Water Management, 98 (5), 784, 2011.

17. LI H.J., YI J., ZHANG J.G., ZHAO Y., SI B.C., HILL R.L., CUI L.L., LIU X.Y.Modeling of soil water and salt dynamics and its effects on root water uptake in Heihe arid wetland, Gansu, China. Water, 7 (5), 2382, 2015.

18. HAJ-AMOR Z., IBRAHIMI M.K., FEKI N., LHOMME J.P., BOURI S. Soil salinisation and irrigation management of date palms in a saharan environment. Environmental Monitoring \& Assessment, 188 (8), 497, 2016.

19. JOVANOVIC N.Z., JARMAIN C., CLERCQ W.D., VERMEULEN T., FEY M.V. Total evaporation estimates from a renosterveld and dryland wheat/fallow surface at the Vo Lvlei nature reserve (south africa). Water Sa, 37 (4), 471, 2011.

20. IBRAHIMI M.K., MIYAZAKI T., NISHIMURA T., IMOTO H. Contribution of shallow groundwater rapid fluctuation to soil salinization under arid and semiarid climate. Arabian Journal of Geosciences, 7 (9), 3901, 2014.

21. HOU L.Z., WANG X.S., HU B.X., SHANG J., WAN L. Experimental and numerical investigations of soil water balance at the hinterland of the Badain Jaran desert for groundwater recharge estimation. Journal of Hydrology, 540, 386, 2016.

22. CHEN Y.X., YANG F.T., SU X.S., XIE N., BAI M., ZHANG X. Estimation of groundwater renewal rate using environmental isotopes in the arid upper peacock river, nw china. Journal of Radioanalytical \& Nuclear Chemistry, 310 (2), 911, 2016.

23. WANG Z., JIN M., SIMUNEK J., GENUCHTEN M.T.V. Evaluation of mulched drip irrigation for cotton in arid northwest China. Irrigation Science, 32 (1), 15, 2014.

24. ZHANG Z.Y., WANG W.K., CHEN L., ZHAO Y.Q., AN K.D., ZHANG L., LIU H.Z. Finite analytic method for solving the unsaturated flow equation. Vadose Zone Journal, 14 (1), 2015.

25. LI X.W., JIN M.G., ZHOU N.Q., HUANG J.O., JIANG S.M., TELESPHORE H. Evaluation of evapotranspiration 
and deep percolation under mulched drip irrigation in an oasis of tarim basin, China. Journal of Hydrology, 538, 677, 2016.

26. ZHANG Z.Y., WANG W.K., YEH T.C.J., CHEN L., WANG Z.F., DUAN L., AN K.D., GONG C.C. Finite analytic method based on mixed-form richards' equation for simulating water flow in vadose zone. Journal of Hydrology, 537, 146, 2016.

27. WANG W.K., ZHANG Z.Y., YEH T.C.J., QIAO G., WANG W.M., DUAN L., HUANG S.Y., WEN J.C. Flow dynamics in vadose zones with and without vegetation in an arid region. Advances in Water Resources, 106, 68, 2017.

28. CHEN W.L., JIN M.G., FERRE T.P., LIU Y.F., XIAN Y., SHAN T.R., PING X. Spatial distribution of soil moisture, soil salinity, and root density beneath a cotton field under mulched drip irrigation with brackish and fresh water. Field Crops Research, 215 (215), 207, 2018.

29. ZHOU J.L., LI Q., GUO Y.C., GUO X.J., LI X.W., ZHAO Y.J., JIA R.L. VLDA model and its application in assessing phreatic groundwater vulnerability: a case study of phreatic groundwater in the plain area of yanji county, xinjiang, china. Environmental Earth Sciences, 67 (6), 1789, 2012.

30. JIRKA S. Modeling nonequilibrium flow and transport processes using hydrus. Vadose Zone Journal, 7 (2), 782, 2008.

31. MUALEM Y. A new model for predicting the hydraulic conductivity of unsaturated porous media. Water Resources Research, 12 (3), 513, 1976.

32. GENUCHTEN M.T.V. A closed-form equation for predicting the hydraulic conductivity of unsaturated soils. Soil Science Society of America Journal, 44 (44), 892, 1980.

33. GENUCHTEN M.T.V. A numerical model for water and solute movement in and below the root zone., Unpub Research Report; USA, 1987.

34. FEDDES R.A., KOWALIK P.J., ZARADNY H. Simulation of field water use and crop yield. Soil Science, 129 (3), 193, 1982.

35. WANG T.J., ZLOTNIK V.A., SIMUNEK J, SCHAAP M.G. Using pedotransfer functions in vadose zone models for estimating groundwater recharge in semiarid regions. Water Resources Research, 45 (4), 546, 2009.

36. XIE T., LIU X.H., SUN T. The effects of groundwater table and flood irrigation strategies on soil water and salt dynamics and reed water use in the Yellow River Delta, China. Ecological Modelling, 222 (2), 241, 2011.

37. CHEN L.J., FENG Q., LI F.R., LI C.S. A bidirectional model for simulating soil water flow and salt transport under mulched drip irrigation with saline water. Agricultural Water Management, 146 (24), 24, 2014.

38. XU C., ZENG W.Z., WU J.W., HUANG J.S. Effects of different irrigation strategies on soil water, salt, and nitrate nitrogen transport. Ecological Chemistry \& Engineering S, 22 (4), 589, 2015.

39. LIU M.X., YANG J.S., LI X.M., LIU G.M., YU M., WANG J. Distribution and dynamics of soil water and salt under different drip irrigation regimes in northwest China. Irrigation Science, 31 (4), 675, 2013.

40. CHEN W.P., LU S.D., PAN N., JIAO W.T. Impacts of long-term reclaimed water irrigation on soil salinity accumulation in urban green land in Beijing. Water Resources Research, 49 (11), 7401, 2013.

41. CHEN L.J., FENG Q., LI F.R., LI C.S. Simulation of soil water and salt transfer under mulched furrow irrigation with saline water. Geoderma, 241, 87, 2015.

42. GEN-JIAN Y.U., HUANG J.S., GAO Z.Y. Study on water and salt transportation of different irrigation modes by the simulation of hydrus model. Journal of Hydraulic Engineering, 44 (7), 826, 2013.

43. WANG X.P., LIU G.M., YANG J.S., HUANG G.H., YAO R.J. Evaluating the effects of irrigation water salinity on water movement, crop yield and water use efficiency by means of a coupled hydrologic/crop growth model. Agricultural Water Management, 185, 13, 2017.

44. GAO X.Y., HUO Z.L., BAI Y.N., FENG S.Y., HUANG G.H., SHI H.B., QU Z.Y. Soil salt and groundwater change in flood irrigation field and uncultivated land: a case study based on 4-year field observations. Environmental Earth Sciences, 73 (5), 2127, 2015.

45. SELIM T., BOUKSILA F., BERNDTSSON R., PERSSON M. Soil water and salinity distribution under different treatments of drip irrigation. Soil Science Society of America Journal, 77 (4), 1144, 2013.

46. GELHAR L.W., CLAIRE W., REHFELDT K.R. A critical review of data on field-scale dispersion in aquifers. Water Resources Research, 28 (7), 1955, 1992.

47. YAKIREVICH A., WEISBROD N., KUZNETSOV M., RIVERA V.C.A., Benavent I., CHAVEZ A.M. Modeling the impact of solute recycling on groundwater salinization under irrigated lands: a study of the alto piura aquifer, peru. Journal of Hydrology, 482 (482), 25, 2013.

48. CHAIYASIT P., DUANGPATRA P., VERASAN V., VUDHIVANICH V. Study on movement of water and salt through soil column and utilization of hydrus-1d program to simulate five scenarios of crop production in salt affected paddy soil. Modern Applied Science, 10 (1), 139, 2015. 